\title{
GenomePlex Whole-Genome Amplification
}

\author{
Nona Arneson, Simon Hughes, Richard Houlston, and Susan Done
}

This protocol was adapted from "PCR-Based Whole Genome Amplification," Chapter 18, in PCR (eds. Hughes and Moody). Scion Publishing Ltd., Oxfordshire, UK, 2007.

\section{INTRODUCTION}

PCR-based whole-genome amplification (WGA) has the goal of generating microgram quantities of genome-representative DNA from picogram or nanogram amounts of starting material. This amplification should introduce little, or ideally no, representational bias. In contrast to other techniques for WGA, PCR-based methods are generally less affected by DNA quality and are more applicable to DNA extracted from various sources (fixed and fresh tissues). GenomePlex WGA, described in this protocol, is a proprietary amplification technology based on nonenzymatic random fragmentation of genomic DNA. The protocol involves conversion of the genome into an in vitro molecular library of DNA fragments, followed by incubation at various temperatures to add adaptor sequences with specific PCR priming sites to both ends of every fragment. The fragment library can then be amplified several 1000 fold to generate milligram quantities of DNA starting with as little as 10-100 ng.

\section{RELATED INFORMATION}

When implementing WGA in the laboratory, it is important to assess the entire experimental process closely, including sample collection, fixation, storage, and initial DNA extraction procedures, as all of these factors can affect DNA quality and thus have some bearing on the selection of the WGA technique. When using WGA, it is important first to validate the method selected and to become proficient in the technique before applying it to actual samples. Irrespective of the method selected, it is essential to establish that the results generated from the amplified DNA are indistinguishable from the results obtained from the original genomic DNA.

The DNA that can be amplified by PCR-based WGA includes DNA extracted from fixed, frozen, or archival tissue; whole blood; buccal swabs; single cells; sorted chromosomes; and laser-capture microdissected tissue (for microdissection of tissues embedded in paraffin, the sections must be deparaffinized prior to microdissection). Genomic DNA may be extracted using a variety of commercially available methods such as the QIAmp DNA mini-kit (QIAGEN). Fixation of tissues can introduce sequence variations and reduce overall DNA quality. When studying such tissues, prior examination of the DNA by agarose gel electrophoresis will help determine the DNA quality. The amplified DNA produced is suitable for a range of downstream genetic assays and thus has the potential for use not only in academic research, but also in commercial, forensic, and diagnostic laboratories.

Protocols for Whole-Genome Amplification by Degenerate Oligonucleotide Primed PCR (DOP-PCR), Whole-Genome Amplification by Improved Primer Extension Preamplification PCR (I-PEP-PCR), Whole-Genome Amplification by Single-Cell Comparative Genomic Hybridization PCR (SCOMP), and Whole-Genome Amplification by Adaptor-Ligation PCR of Randomly Sheared Genomic DNA (PRSG) are also available in this issue of CSH Protocols. 


\section{MATERIALS}

CAUTIONS AND RECIPES: Please see Appendices for appropriate handling of materials marked with $<!>$, and recipes for reagents marked with $<\mathbf{R}>$.

\section{Reagents}

Agarose (Sigma)

DNA size marker (100-bp ladder; Invitrogen)

$<$ !>Ethidium bromide (10 $\mathrm{mg} / \mathrm{mL}$; Sigma)

Genomic DNA (1-10 $\mathrm{ng} / \mu \mathrm{L})$

GenomePlex Whole Genome Amplification kit (Sigma)

The GenomePlex kit was originally developed by Rubicon Genomics but is now available from Sigma. The constituents of the GenomePlex WGA kit buffers are proprietary and are therefore unknown.

The kit includes 10X Fragmentation buffer, $1 \times$ Library Preparation buffer, Library Stabilization solution, Library Preparation enzyme, and 10X Amplification Master Mix.

$\mathrm{H}_{2} \mathrm{O}$ (nuclease-free) (Promega)

Orange loading dye (6X) (Fermentas)

$<$ !>Phenol:chloroform or PCR purification kit (see Step 15)

Taq DNA polymerase (JumpStart; Sigma)

It is strongly recommended to use the JumpStart or BD TITANIUM Taq DNA polymerase, as both have been optimized for use with the GenomePlex kit. Other sources of Taq DNA polymerase may not produce optimal results.

$<\mathrm{R}>$ TBE buffer ( $1 \mathrm{X}$ diluted from a $10 \mathrm{X}$ stock at $\mathrm{pH} 8$; may also be obtained from Sigma)

\section{Equipment}

Centrifuge

Electrophoresis apparatus

Ice

Spectrophotometer

Thermal cycler

$<$ ! $>$ UV light

Vortex mixer or pipettes for mixing solutions

\section{METHOD}

\section{GenomePlex Fragmentation}

1. Combine the following reagents, and mix by pipetting or brief vortexing:

$10 \mu \mathrm{L}(10-100 \mathrm{ng}$ final concentration)

$1 \mu \mathrm{L}$
DNA sample

10X Fragmentation buffer (blue-capped tube in the GenomePlex Whole Genome Amplification kit)

Users should prepare at least two GenomePlex reactions for each sample, as this will provide a greater yield of DNA. In addition, better results have been obtained in downstream applications when the products from at least two reactions are combined.

When handling many samples (>20), use multiwell strips or 96-well PCR plates, as this will help decrease the set-up time. However, caution must be taken when removing the strip caps to avoid cross-contamination of tube contents. For 96-well plates, use adhesive metal or plastic films. The advantage of these (vs. strip caps) is that they do not need to be removed and can be pierced using a pipette tip to allow the addition of the Library Preparation solution (Step 4). The plate can then be resealed by placing a second film over the top of the first film.

2. Consolidate the sample by centrifugation $(5-10 \mathrm{sec})$, and incubate for $4 \mathrm{~min}$ at $95^{\circ} \mathrm{C}$ in a thermal cycler.

As stated by Sigma in the manual for the GenomePlex kit, adhering to this incubation time is essential, as longer 
or shorter times can affect results. In our experience, however, if degraded DNA is used, decreasing the fragmentation time in 30-sec increments can improve results.

3. Cool the sample for 5 min on ice.

\section{Library Preparation}

4. Add $2 \mu \mathrm{L}$ of $1 \mathrm{X}$ Library Preparation buffer (green-capped tube) and $1 \mu \mathrm{L}$ of Library Stabilization solution (yellow-capped tube) to each sample. Mix the sample by pipetting or brief vortexing.

5. Consolidate the sample by centrifugation $(5-10 \mathrm{sec})$, and incubate for $2 \mathrm{~min}$ at $95^{\circ} \mathrm{C}$ in a thermal cycler.

6. Cool the sample for $5 \mathrm{~min}$ on ice, and consolidate by centrifugation $(5-10 \mathrm{sec})$.

7. Add $1 \mu \mathrm{L}$ of Library Preparation enzyme (orange-capped tube), mix by pipetting or vortexing, and centrifuge briefly.

8. Incubate the samples in a thermal cycler using the following conditions:

\begin{tabular}{ll} 
Temperature & Time \\
\hline $16^{\circ} \mathrm{C}$ & $20 \mathrm{~min}$ \\
$24^{\circ} \mathrm{C}$ & $20 \mathrm{~min}$ \\
$37^{\circ} \mathrm{C}$ & $20 \mathrm{~min}$ \\
$75^{\circ} \mathrm{C}$ & $5 \mathrm{~min}$
\end{tabular}

9. Store the reaction mixtures for up to $3 \mathrm{~d}$ at $-20^{\circ} \mathrm{C}$, or continue with PCR amplification.

The effect of long-term storage on WGA DNA and subsequent downstream applications has not been assessed.

\section{GenomePlex PCR Amplification}

10. Per reaction, combine the following reagents:
$7.5 \mu \mathrm{L}$
10X Amplification Master Mix (red-capped tube)
$47.5 \mu \mathrm{L}$
Sterile $\mathrm{H}_{2} \mathrm{O}$
$5 \mu \mathrm{L}$
JumpStart Taq DNA polymerase
$15 \mu \mathrm{L}$
Library preparation (from Step 9)

11. Mix the reaction constituents thoroughly by pipetting or vortexing, and centrifuge briefly.

12. Use the following PCR profile for amplification:

\begin{tabular}{lll} 
Number of cycles & Temperature & Time \\
\hline 1 & $95^{\circ} \mathrm{C}$ & $3 \mathrm{~min}$ \\
14 & $94^{\circ} \mathrm{C}$ & $15 \mathrm{seC}$ \\
& $65^{\circ} \mathrm{C}$ & $5 \mathrm{~min}$
\end{tabular}

If more than one reaction has been set up for each sample (which is recommended), combine reactions after amplification.

13. Determine the size of the products as follows:

i. Mix $5 \mu \mathrm{L}$ of the reaction mix with $1 \mu \mathrm{L}$ of $6 \mathrm{X}$ orange loading dye solution.

ii. Resolve the aliquot by CSH Protocols article Agarose Gel Electrophoresis using a $1 \%$ agarose gel containing $20 \mu \mathrm{g}$ of ethidium bromide $(10 \mathrm{mg} / \mathrm{mL})$ per $100 \mathrm{~mL}$ of agarose, beside a DNA size marker.

iii. Detect the DNA smears under UV light.

The size of the amplification product is dependent on the quality of the starting DNA. If high-molecularweight DNA (extracted from fresh tissue or cells) was used, the amplification product smear will range from 50 to $2000 \mathrm{bp}$. However, if low-molecular-weight DNA (from fixed tissue) was used, the size of the amplification product smear will generally be $<500 \mathrm{bp}$.

See Troubleshooting. 
14. Store the reaction mixtures at $-20^{\circ} \mathrm{C}$ prior to purification.

15. Clean the GenomePlex WGA products to remove unincorporated primers and other reaction constituents that may interfere with downstream applications.

Any PCR product clean-up method is acceptable, including the MinElute 96 UF PCR Purification kit (QIAGEN), QIAquick PCR Purification kit (QIAGEN), DNA Clean \& Concentrator 5 (Genetix), Microcon YM-30 Centrifugal Filter Unit (Millipore), or phenol:chloroform extraction (see CSH Protocols article Purification of Nucleic Acids by Extraction with Phenol:Chloroform).

16. Quantitate the GenomePlex WGA products using spectrophotometry. See Troubleshooting.

\section{TROUBLESHOOTING}

Problem: There is amplification in the negative control.

[Step 13.iii]

Solution: Owing to the manipulation of PCR products in all PCR-based WGA methods, the reactions can easily be contaminated. If negative controls produce a DNA smear, several steps can be tried to eliminate this:

- Repeat using fresh reagents.

- Use filtered tips to avoid introduction of contaminants via aerosol from the pipette.

- Physically separate the areas in the laboratory where reactions are set up. Prepare and pipette the PCR mixture at one bench, and then add the DNA to the reaction in a different location in the laboratory. Also, use different pipettes for reaction preparation and pipetting of DNA.

- Aliquot all reaction constituents; if an aliquot becomes contaminated, only that aliquot will be lost and not the entire stock.

Problem: Unpredictable amplification is observed.

[Step 13.iii]

Solution: A positive control (i.e., starting with 50 ng of good-quality genomic DNA) can be used to ensure that the reaction is working optimally. In addition:

- Store small aliquots of dNTPs and oligonucleotides, as repeated freeze/thaw cycles of a single stock can affect the integrity of these reagents and thereby affect the efficiency of WGA.

- The starting concentration of DNA is crucial. Best results are obtained when starting with $10 \mathrm{ng}$ (or more) of DNA extracted from fresh tissue/blood or $100 \mathrm{ng}$ of DNA extracted from fixed tissue. Lower amounts of DNA ( $<10 \mathrm{ng}$ from fresh tissue or $<100 \mathrm{ng}$ from fixed tissue) will generate amplification products, but results obtained in downstream applications may not be faithful to the result that would have been obtained from nonamplified DNA.

- If a positive control PCR using 10-100 ng of good-quality, high-molecular-weight DNA produces good results, the assay problems are a product of the DNA sample under investigation. However, if the positive control does not amplify, it suggests a problem with the reaction constituents or the thermal cycling. In such cases, use fresh aliquots of reagents, and repeat the experiment. If the problem still persists, it may be necessary to order fresh reagents.

Problem: The amplification smear contains smaller DNA fragments than expected.

[Step 13.iii]

Solution: The efficiency of amplification is dependent on the quality of the starting DNA, and the size of the amplification products is also template-dependent. Tissue fixation causes degradation of template DNA within the sample. If the template is degraded, as is DNA from formalin-fixed, paraffin-embedded material, the smear will be smaller in size. Unfortunately, there is no way of improving this; thus care must be taken when using such products for downstream applications, because there may be more bias in these samples. Although PCR-based WGA is tolerant to mild or moderate DNA degradation and will amplify DNA with an average length of approximately 200 $\mathrm{bp}$, in this case it is essential to use increased quantities of starting DNA (100 ng) to guarantee a satisfactory yield of final product. Moderate to severe degradation will reduce WGA efficiency and subsequently decrease the quality of results obtained in downstream applications. 
Problem: There is insufficient DNA for downstream reactions.

[Step 16]

Solution: Combine at least two individual WGA amplifications for each DNA to be studied, as this produces better results in downstream experiments.

Problem: Unpredictable results are obtained from downstream applications.

Solution: Successful PCR-based WGA and successful downstream results depend on the quality of starting DNA. For instance, if there is ineffective PCR amplification of a specific control gene with nonamplified DNA, negative results after WGA are to be expected. If using laser-capture microdissected material, perform a standard control PCR and a PCR using DNA from nonlaser-capture microdissected tissue prior to WGA. In some cases, it may be necessary to try different amounts of amplified DNA in downstream PCR amplification procedures, for example, 12, 25, 50, and $100 \mathrm{ng}$.

\section{DISCUSSION}

When using GenomePlex for region-specific PCR, we have found the ideal range of PCR size to be 100$600 \mathrm{bp}$. If GenomePlex is used with DNA from formalin-fixed, paraffin-embedded tissues, it is likely that this range will be smaller. Microsatellite analysis of GenomePlex products worked well in our hands for tri- and tetranucleotide repeats, but the amplification of dinucleotide repeats did not demonstrate concordance between the amplified and nonamplified samples. The use of GenomePlex to amplify DNA obtained from formalin-fixed, paraffin-embedded tissue provides good arraycomparative genomic hybridization (CGH) results (Little et al. 2006). Concordance is $99.89 \%$ when compared with nonamplified DNA, determined using the Illumina single-nucleotide polymorphism (SNP) platform (Barker et al. 2004). However, SNP genotyping using the Affymetrix experimental protocol is not recommended for GenomePlex WGA products (data not shown) because of poor results. This is likely due to the loss of Xbal restriction sites required for the protocol, although this has yet to be tested.

\section{REFERENCES}

Barker, D.L., Hansen, M.S., Faruqi, A.F., Giannola, D., Irsula, O.R., Lasken, R.S., Latterich, M., Makarov, V., Oliphant, A., and Pinter, J.H. 2004. Two methods of whole-genome amplification enable accurate genotyping across a 2320-SNP linkage panel. Genome Res. 14: 901-907.
Little S.E, Vuononvirta, R., Reis-Filho, J.S., Natrajan, R., Iravani, M. Fenwick, K., Mackay, A., Ashworth, A., Pritchard-Jones, K., and Jones, C. 2006. Array CGH using whole genome amplification of fresh-frozen and formalin-fixed, paraffin-embedded tumor DNA. Genomics 87: 298-306. 


\section{GenomePlex Whole-Genome Amplification}

Nona Arneson, Simon Hughes, Richard Houlston and Susan Done

Cold Spring Harb Protoc; doi: 10.1101/pdb.prot4920

\begin{aligned} & \hline $\begin{array}{r}\text { Email Alerting } \\ \text { Service }\end{array}$ Receive free email alerts when new articles cite this article - click here. \\ & \hline $\begin{array}{c}\text { Subject } \\ \text { Categories }\end{array}$ Browse articles on similar topics from Cold Spring Harbor Protocols. \\ & Amplification of DNA by PCR (85 articles) \\ & Bioinformatics/Genomics, general (192 articles) \\ & DNA Sequencing (96 articles) \\ & Genetic Variation (86 articles) \\ & Genetics, general (374 articles) \\ & Genome Analysis (191 articles) \\ & Genomic DNA (135 articles) \\ & Genomic Libraries (66 articles) \\ & Libraries (147 articles) \\ & Libraries, general (113 articles) \\ & Molecular Biology, general (1293 articles) \\ & Polymerase Chain Reaction (PCR) (139 articles) \\ & Polymerase Chain Reaction (PCR), general (184 articles) \\ & \hline\end{aligned}

